\title{
Trace Level Arsenic Quantification through Cloud Point Extraction: Application to Biological and Environmental Samples
}

\author{
Kempahanumakkagari Suresh Kumar and Malingappa Pandurangappa \\ Department of Studies in Chemistry, Bangalore University, Central College Campus, Dr. Ambedkar Veedhi, Bangalore 560001 , India \\ Correspondence should be addressed to Malingappa Pandurangappa, mprangachem@gmail.com
}

Received 17 October 2011; Accepted 30 November 2011

Academic Editor: Josefa León

Copyright (C 2012 K. Suresh Kumar and M. Pandurangappa. This is an open access article distributed under the Creative Commons Attribution License, which permits unrestricted use, distribution, and reproduction in any medium, provided the original work is properly cited.

\begin{abstract}
A sensitive solvent-free extraction protocol for the quantification of arsenic at trace level has been described. It is based on the reaction of arsenic $(\mathrm{V})$ with molybdate in acidic medium in presence of antimony (III) and ascorbic acid as a reducing agent to form a blue-colored arsenomolybdenum blue complex. The complex has been extracted into surfactant phase using Triton X-114, and its absorbance was measured at $690 \mathrm{~nm}$. The detection limit, working range, and the relative standard deviation were found to be $1 \mathrm{ng} \mathrm{mL} L^{-1}, 10-200 \mathrm{ng} \mathrm{mL}^{-1}$, and 1.2\%, respectively. The effect of common ions was studied, and the method has been applied to determine trace levels of As(III) and As(V) from a variety of samples like environmental, biological, and commercially procured chemicals.
\end{abstract}

\section{Introduction}

Arsenic is one of the common contaminant of ground water which has been found to adversely affect human health at levels as low as $10 \mu \mathrm{g} \mathrm{L}^{-1}$ [1]. It has a lethal dosage at $50 \%$ of the population of $763 \mathrm{mg} \mathrm{kg}^{-1}$ of body mass. The maximum contaminant level (MCL) prescribed by the United States Environment Protection Agency (USEPA) for arsenic is $50 \mu \mathrm{g} \mathrm{L}-1$ in drinking water. The World Health Organization (WHO) has recommended MCL for arsenic in drinking water as low as $10 \mu \mathrm{g} \mathrm{L}^{-1}[1]$. Arsenic is very similar to phosphorous in some physical and chemical properties; that is, the oxides of both elements form colorless and odorless crystalline structures or compounds which are hygroscopic and soluble in water. Due to these similarities, arsenic can often substitute for phosphorous in biological systems [2]. It is well known that arsenic inhibits the key metabolic enzyme pyruvate dehydrogenase and arsenate competes with phosphate for the enzyme which disturbs ATP production and ultimately uncouples oxidative phosphorylation. This inhibition results in the reduction of the energy linked $\mathrm{NAD}^{+}$, mitochondrial respiration, and ATP synthesis. The presence of arsenic in the body also increases hydrogen peroxide production which can lead to the formation of reactive oxygen species. Consumption of arsenic contaminated matrices like drinking water, rice, and vegetables lead to various health problems like hyperkeratosis, respiratory, and cardiovascular disorders [3]. Arsenic has been extensively used in several applications mainly in wood preservation, in the production of insecticides, herbicides, drugs, and feed additives, and in poison preparation [4-6].

Among the various forms of arsenic, inorganic species like arsenite and arsenate were proved to be more toxic than that of organoarsenicals [3]. Quantification of inorganic arsenic from water samples has been always a challenging task especially at ultratrace level. Instrumental methods like atomic absorption spectrophotometry (AAS), high-performance liquid chromatography (HPLC), and inductively coupled plasma mass spectrophotometry (ICPMS) have been extensively used to quantify this toxic metal ion at trace level $[7,8]$. Most of these techniques rely on expensive apparatus, skilled operators, complicated procedures, and time-consuming sample preparation procedures. Hence, spectrophotometric methods find wide spread use in determining metal ions at trace level from a variety of sample matrices due to their easy adaptability even in modestly equipped laboratories. Many of these spectrophotometric methods are less sensitive, and toxic organic solvents like 
benzene, pyridine, and chloroform were used for analyte extraction $[9,10]$. One of these methods requires hydride generation facility which results in the formation of arsenic hydride which is known to be poisonous [11]. Recently, a method has been reported based on microparticle formation of methylene blue dye. The intensity of the color has been quenched by arsenic, and it gave a very low detection limit of $4 \mathrm{ng} \mathrm{mL}^{-1}$ [12]. Low-cost test kits have been available in the past, but they can be used in higher concentration range, that is, $100-3000 \mu \mathrm{g} \mathrm{L}^{-1}$, which is not sensitive enough to monitor low levels of metal ion in drinking water and other treated industrial effluents. Hence we require inexpensive and sensitive methods for monitoring the arsenic at trace level. Recently, cloud-point-extraction (CPE-) based methods have been extensively used to facilitate preconcentration and separation of the analyte from complex matrices [13].

Separation and preconcentration of the analyte can be easily achieved by using surfactant in place of organic solvent [13]. The presence of surfactant not only facilitates extraction of analyte efficiently but also enhances the sensitivity of the method [14]. Hence, surfactant-mediated extraction procedures provide very good efficiency in extracting the analyte from a large volume of aqueous solution. This protocol is simple, highly efficient, and less expensive and restricts the use of toxic organic solvents. The present paper describes a simple cloud point extractive determination of arsenic as arsenomolybdenum blue using nonionic surfactant, that is, Triton X-114 at room temperature. The proposed method is simple and sensitive, and it has been successfully applied to determine trace level arsenic from different environmental and biological samples.

\section{Experimental}

2.1. Instrumentation. Absorbance measurements were made using a Shimadzu Scanning Spectrophotometer (model UV$3101 P C)$ with $1 \mathrm{~cm}$ quartz cuvettes. Calibrated centrifuge tubes with $15 \mathrm{~mL}$ volume capacity were used to accelerate the phase separation. All pH measurements were carried out using Control Dynamics digital pH meter (model APX 175). ICPAES analysis was carried out using Jobin Yvon Horiba Spectrometer (model Ultima 2).

2.2. Reagents and Solutions. All chemical reagents used were of Analar grade, and distilled water was used throughout the experiments. Stock arsenate solution $\left(1000 \mu \mathrm{g} \mathrm{mL}^{-1}\right)$ was prepared by dissolving $0.416 \mathrm{~g}$ of $\mathrm{Na}_{2} \mathrm{HAsO}_{4} \cdot 7 \mathrm{H}_{2} \mathrm{O}$ AR (SD Fine Chem Ltd., Mumbai, India). Ammonium molybdate solution of $0.015 \mathrm{~mol} \mathrm{~L}^{-1}$ was prepared weekly by dissolving $1.85 \mathrm{~g}\left(\mathrm{NH}_{4}\right)_{6} \mathrm{Mo}_{7} \mathrm{O}_{24} \cdot 7 \mathrm{H}_{2} \mathrm{O}$ (Merck, Mumbai, India) in $100 \mathrm{~mL}$ distilled water and storing in refrigerator. About $0.008 \mathrm{~mol} \mathrm{~L}^{-1}$ of Sb (III) was prepared by dissolving $0.267 \mathrm{~g}$ of potassium antimony tartrate (Biddle Sawyer \& Co Ltd., Mumbai, India) in $100 \mathrm{~mL}$ distilled water. Ascorbic acid solution (SD Fine Chem Ltd., Mumbai, India) of about $0.01 \mathrm{~mol} \mathrm{~L}^{-1}$ was prepared by dissolving $0.176 \mathrm{~g}$ in $100 \mathrm{~mL}$ distilled water and storing in refrigerator. Sulfuric acid $1.25 \mathrm{~mol} \mathrm{~L}^{-1}$ was prepared by diluting appropriate amount of concentrated acid in cooled distilled water. Triton X-114
(ACROS ORGANICS, NJ, USA) (4\% v/v) stock solution was prepared by dissolving $4 \mathrm{~mL}$ of concentrated solution in hot distilled water. $\mathrm{H}_{2} \mathrm{O}_{2}(30 \% \mathrm{w} / \mathrm{v})$ (Qualigens, Mumbai, India) was used for sample digestion.

\subsection{Sample Collection and Preparation}

2.3.1. Water Samples. The water samples were collected using polyethylene containers from polluted lake where painted clay idols were immersed after festival procession. The water samples were filtered through Whatman filter paper to remove the suspended particulate matter. Then, $5 \mathrm{~mL}$ of the diluted sample was used to determine the arsenic (V) and another $5 \mathrm{~mL}$ aliquot of sample was treated with $1 \mathrm{~mL}$ each of concentrated nitric acid and $\mathrm{H}_{2} \mathrm{O}_{2}$ for the determination of total arsenic $[\mathrm{As}(\mathrm{III})+\mathrm{As}(\mathrm{V})]$.

2.3.2. Soil Samples. The soil samples were collected from the agricultural field and soil sludge samples from the pond bed where painted clay idols were immersed. Both samples were collected from the site and stored in polyethylene bags. The soil samples were air dried, and known weight $(100 \mathrm{~g})$ of sample was placed in a $250 \mathrm{~mL}$ beaker and extracted four times with $5 \mathrm{~mL}$ portions of concentrated hydrochloric acid each time. The combined extract was boiled for about $30 \mathrm{~min}$, then the solution was cooled and diluted to $50 \mathrm{~mL}$ with distilled water. $5 \mathrm{~mL}$ aliquot of diluted sample was used for $\mathrm{As}(\mathrm{V})$ determination by the proposed method. Another aliquot of $5 \mathrm{~mL}$ was treated with $1 \mathrm{~mL}$ each of concentrated nitric acid and $\mathrm{H}_{2} \mathrm{O}_{2}$ solution to determine total arsenic.

2.3.3. Vegetable Samples. The spinach and tomato leaves were collected from local market. They were dried in sun light and grinded into fine powder. $100 \mathrm{~g}$ of finely powdered and sieved sample was placed in a beaker. $10 \mathrm{~mL}$ each of nitric acid and sulfuric acids were added and heated to $100^{\circ} \mathrm{C}$ for $20 \mathrm{~min}$, in fume hood. The solutions were cooled, treated with $10 \mathrm{~mL}$ of perchloric acid, and heated again in fume hood for $5 \mathrm{~min}$, until the dense fumes of sulphur dioxide disappear completely. Then, solutions were cooled and $1 \mathrm{~mL}$ of $\mathrm{HCl}$ was added to remove any heavy metal ions present in the sample. The filtered solutions were diluted to $100 \mathrm{~mL}$ using distilled water. Then, $5 \mathrm{~mL}$ aliquots of diluted samples were used for the estimation of $\mathrm{As}(\mathrm{V})$ content as well as total arsenic after treating the sample aliquot with $1 \mathrm{~mL}$ each of concentrated nitric acid and hydrogen peroxide.

\subsubsection{Biological Samples}

Urine Sample. Urine samples were collected in sterilized glass containers from male individuals, and $10 \mathrm{~mL}$ of sample was diluted to five times. The diluted samples were deproteinated by treating with $2 \mathrm{~mL}$ of trichloroacetic acid (30\%), and the residue has been removed by centrifugation. The filtrate was treated with $5 \mathrm{~mL}$ each of concentrated nitric acid and $\mathrm{H}_{2} \mathrm{O}_{2}$ to oxidize any $\mathrm{As}(\mathrm{III})$ present to $\mathrm{As}(\mathrm{V})$ in the sample. Then, the solution was diluted to $100 \mathrm{~mL}$ and five $\mathrm{mL}$ aliquots of diluted samples were subjected for the analysis of arsenic content. 
Nail and Hair Samples. Hair and Nail samples were collected from adults and washed thoroughly with distilled water followed by acetone and finally dried in an oven at $100^{\circ} \mathrm{C}$. About $0.2 \mathrm{~g}$ of dried samples were placed in $250 \mathrm{~mL}$ beakers separately and, $12 \mathrm{~mL}$ of concentrated $\mathrm{HNO}_{3}$ followed by $2 \mathrm{~mL}$ of $\mathrm{HClO}_{4}$ were added. The contents were digested by heating on a sand bath for about $45 \mathrm{~min}$; after the digestion, the solutions were cooled and treated with $5 \mathrm{~mL}$ of $\mathrm{H}_{2} \mathrm{O}_{2}$. The reaction mixture was heated again to dryness at $200^{\circ} \mathrm{C}$ to yield a white residue. Then, $10 \mathrm{~mL}$ of $1 \mathrm{~mol} \mathrm{~L}^{-1} \mathrm{H}_{2} \mathrm{SO}_{4}$ was added to the beaker and the contents were heated at $100^{\circ} \mathrm{C}$ for $1 \mathrm{~h}$ and diluted to $50 \mathrm{~mL}$. Five $\mathrm{mL}$ aliquots of these solutions were used to estimate the arsenic content.

2.4. Chemicals. The commercially procured laboratory chemicals for which the assay has been specified have been used to quantify the arsenic content. One gram of sample was dissolved in water and then treated with $5 \mathrm{~mL}$ each of concentrated nitric acid followed by $\mathrm{H}_{2} \mathrm{O}_{2}$. The solutions were diluted to $100 \mathrm{~mL}$, and $5 \mathrm{~mL}$ aliquots were used for the analysis of total arsenic content.

2.5. Amaranth Dye. $1 \mathrm{~g}$ of dye sample was dissolved in water and then, treated with $5 \mathrm{~mL}$ each of concentrated nitric and $\mathrm{H}_{2} \mathrm{O}_{2}$. The $\mathrm{pH}$ of the solution was adjusted to 5 by adding acetate buffer solution and made up to $100 \mathrm{~mL}$. Then, $5 \mathrm{~mL}$ aliquot of diluted sample was used for the analysis.

2.6. Procedure. Suitable aliquots of arsenate solution (arsenic concentration $10-200 \mathrm{ng} \mathrm{mL}^{-1}$ ) were taken in $10 \mathrm{~mL}$ volumetric flasks. Then, $2 \mathrm{~mL}$ of $1.25 \mathrm{~mol} \mathrm{~L}^{-1}$ sulfuric acid, $0.2 \mathrm{~mL}$ of $0.008 \mathrm{~mol} \mathrm{~L}^{-1}$ antimony (III), $1.2 \mathrm{~mL}$ of $0.015 \mathrm{~mol} \mathrm{~L}^{-1}$ ammonium molybdate, and $0.5 \mathrm{~mL}$ of $0.01 \mathrm{~mol} \mathrm{~L}^{-1}$ ascorbic acid were added and allowed for 10 minutes for the formation of arsenomolybdenum blue complex. Then, $2 \mathrm{~mL}$ of Triton X-114 (4\% v/v) has been added and the solutions were diluted to the mark. These solutions were transferred into $30 \mathrm{~mL}$ centrifuge tubes and phase separation was achieved by centrifuging them at $3800 \mathrm{rpm}$ for $5 \mathrm{~min}$. The centrifuge tubes were cooled in an ice bath to harden the viscous phase of the surfactantrich micellar phase. Then, the aqueous phase was separated by simple decantation method. The surfactant-rich micellar phase was homogenized by the addition of ethanol and made up to $5 \mathrm{~mL}$. The absorbance values were measured at $690 \mathrm{~nm}$ against the reagent blank.

\section{Results and Discussion}

The proposed method is based on the reaction of arsenic (V) with molybdate to form arsenomolybdate and its reduction to arsenomolybdenum blue complex in presence of a reducing agent. This reaction has been proposed based on the phosphate's reaction with molybdate to form phosphomolybdenum blue in acidic medium and its application to water samples through cloud point extraction [15]. The reaction has been explored to develop a simple and sensitive spectrophotometric method to measure arsenic at nanogram level concentrations. The arsenomolybdate formed in acidic

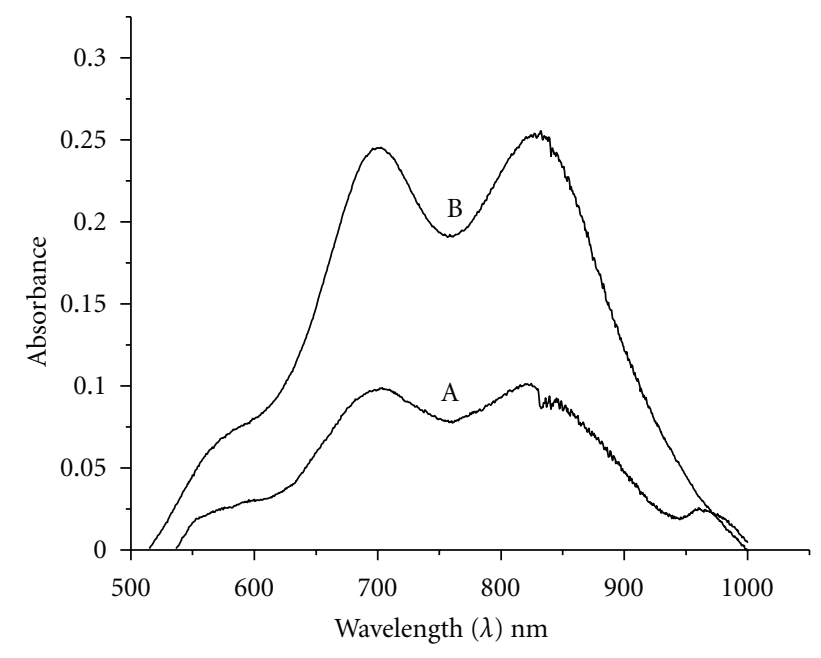

$$
\begin{aligned}
& \text { A Reagent blank } \\
& \text { B Sample }
\end{aligned}
$$

FigURE 1: Absorption spectra of arsenomolybdenum blue complex after cloud point extraction.

medium with molybdate can be reduced to arsenomolybdenum blue complex with antimony (III) in presence of ascorbic acid as reducing agent. The blue-colored complex exhibited absorption maximum at $840 \mathrm{~nm}$ in aqueous condition. Surfactants have been extensively used to sensitize the reaction or to separate the analyte phase without using organic solvent as a medium. Hence, a nonionic surfactant has been used to extract the arsenomolybdenum blue complex by cloud point method at room temperature. The colored complex has exhibited two absorption maxima one at 690 and another at $840 \mathrm{~nm}$ in presence of surfactant (Figure 1). The nature of dual absorption maxima of this complex is unknown till now, and the investigations are in progress to find its abnormal behavior. However, the signal to noise ratio is much superior at $690 \mathrm{~nm}$ when compared to $840 \mathrm{~nm}$, hence all absorbance measurements have been carried out at $690 \mathrm{~nm}$ in the present investigations.

3.1. Optimization Study. The initial studies were carried out by extracting the formed arsenomolybdenum blue complex into nonionic surfactants like Triton X-100 and Triton X-114 as the TX series of nonionic surfactants have several advantages over other surfactants like commercial availability, low toxicity, low cloud point formation temperature and high density of the surfactant-rich micellar phase [13]. The quantitative extraction of the complex was obtained by both the surfactants, but, in case of Triton X-100, heating is required for cloud formation but in presence of Triton X-114, cloud formation takes place at room temperature. Hence, Triton X-114 was used as a micellar phase to preconcentrate the analyte species before absorbance measurement. All the parameters influencing the complex formation and cloud point extraction have been optimized.

3.1.1. Effect of Acidity. The arsenomolybdenum blue complex forms in acidic medium; hence, the effect of sulfuric acid 


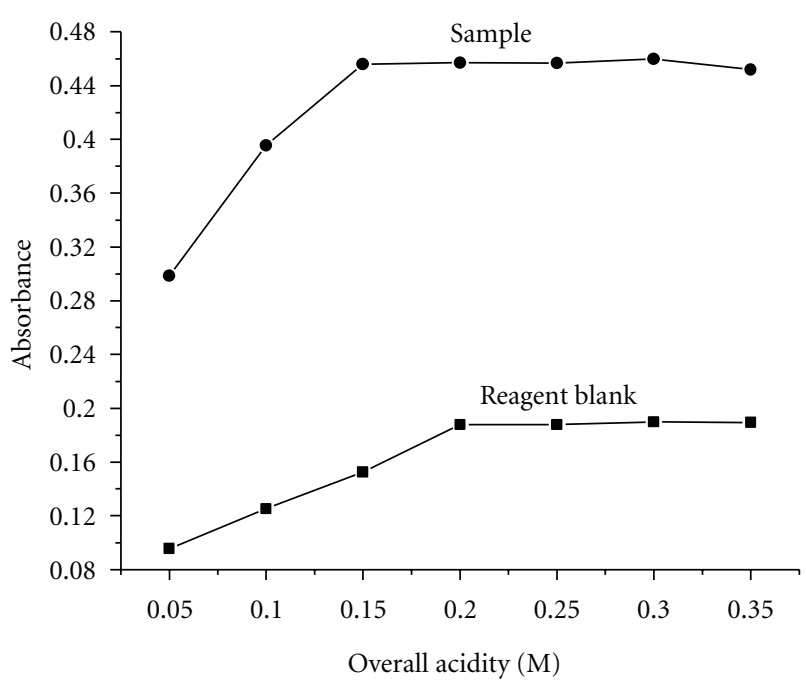

Figure 2: Effect of overall acidity.

concentration on complex formation has been studied. The higher absorbance values corresponding to the sample versus reagent blank were obtained at an overall acidity value of $0.25 \mathrm{M}$. The required acidity was achieved by the addition of $2 \mathrm{~mL}$ of $1.25 \mathrm{~mol} \mathrm{~L}^{-1}$ sulfuric acid and used in all further studies (Figure 2).

3.1.2. Effect of Surfactant. The effect of surfactant concentration on the quantitative phase separation of analyte through micelle is a crucial parameter in cloud-point-extraction based methods. Hence, we have examined two nonionic surfactants like Triton X-100 and Triton X-114 for the quantitative separation of the complex. Quantitative extraction of the complex from the aqueous phase was obtained by both surfactants, but the extraction of the complex at room temperature was achieved only with Triton X-114. The high density of Triton X-114 facilitates quick phase separation which can be easily achieved by simple centrifugation [16]. In case of Triton X-100, heating is required to attain cloud point temperature whereas Triton X-114 attains clouding at normal condition itself, that is, at room temperature [9]. Hence, Triton X-114 has been selected as a micellar phase for analyte separation. Quantitative extraction of the complex was achieved at $0.8 \%(\mathrm{v} / \mathrm{v})$. The required surfactant concentration was achieved by the addition of $2 \mathrm{~mL}$ of $4 \%$ surfactant solution (Figure 3 ).

3.1.3. Effect of Ammonium Molybdate. The effect of ammonium molybdate concentration was carried out in order to get maximum sample absorbance with minimum blank value. The absorbance value of surfactant-rich phase increases with increase in molybdate concentration and remains constant at molybdate concentration beyond $1.2 \times 10^{-3} \mathrm{~mol} \mathrm{~L}^{-1}$. Hence, the required concentration was achieved by the addition of $1.2 \mathrm{~mL}$ of $0.015 \mathrm{~mol} \mathrm{~L}^{-1}$ molybdate solution (Figure 4). Similarly, the effect of Sb (III) concentration on the complex formation was also studied and the maximum absorbance value for sample was observed at $1 \times 10^{-3} \mathrm{~mol} \mathrm{~L}^{-1}$

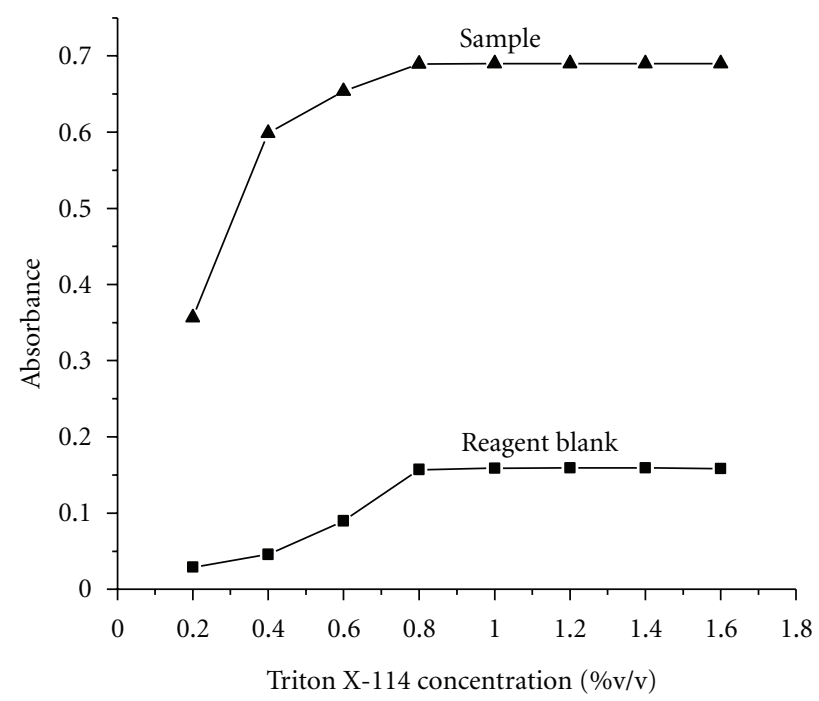

Figure 3: Effect of Triton X-114 concentration.

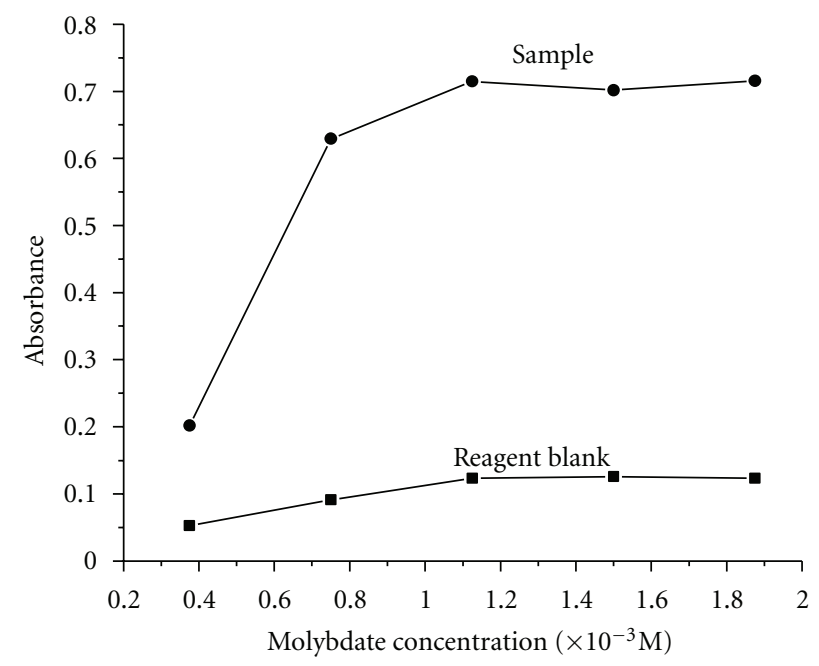

FIGURE 4: Effect of molybdate concentration.

concentration. It was achieved by adding $0.2 \mathrm{~mL}$ of $0.008 \mathrm{~mol} \mathrm{~L}^{-1} \mathrm{Sb}$ (III) solution.

3.1.4. Effect of Ascorbic Acid. Various reducing agents like sulfate and ascorbic acid were used to reduce the arsenomolybdate to arsenomolybdenum blue. Ascorbic acid is preferred over sulfate because sulfate is a good reducing agent in neutral condition whereas the complex formation takes place at acidic condition. The optimum concentration of ascorbic acid required for the complex formation has been found to be $4 \times 10^{-3} \mathrm{~mol} \mathrm{~L}^{-1}$. The required concentration has been achieved by the addition of $0.4 \mathrm{~mL}$ of $0.01 \mathrm{~mol} \mathrm{~L}^{-1}$ (Figure 5).

\subsubsection{Effect of Time and Temperature on Cloud Point Extrac-} tion. The effects of time and temperature on the cloud point extraction of arsenomolybdenum blue complex from the aqueous phase into micellar phase have been studied. 


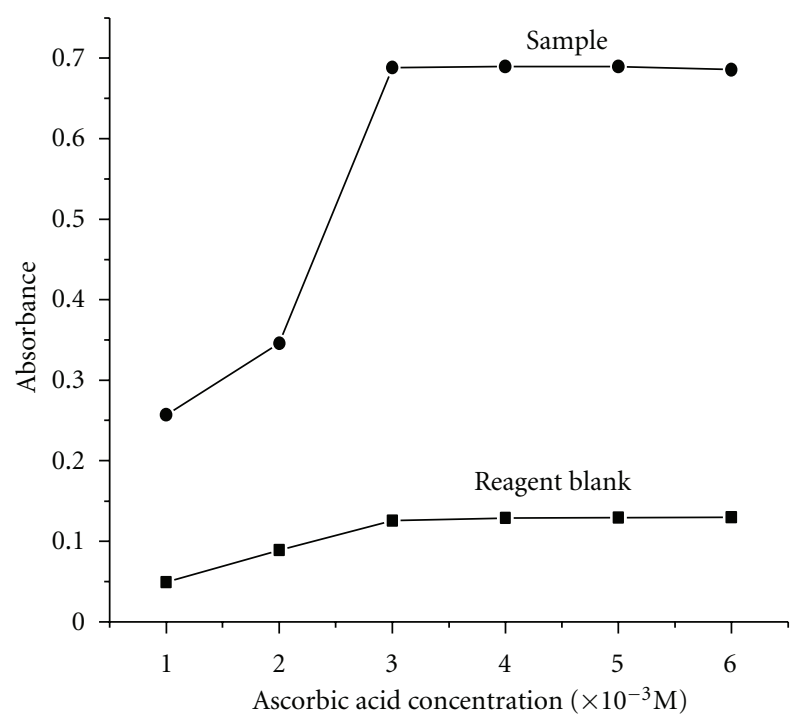

FIGURE 5: Effect of ascorbic acid.

The cloud point formation occurs at room temperature as Triton X-114 cloud point temperature at room temperature. Then, CPE of the complex is going to complete within $10 \mathrm{~min}$, that is, centrifuging the solution for $5 \mathrm{~min}$ at $3800 \mathrm{rpm}$ to separate aqueous phase from micellar phase and cooling the separated micellar and aqueous phase in ice bath for $5 \mathrm{~min}$ in order to increase the viscosity of the surfactant phase which facilitates easy decantation of aqueous phase from the tube. The separated surfactant phase should be dissolved in suitable organic solvents to decrease the viscosity in order to measure its absorbance value. Various solvents like ethanol, methanol, and acetonitrile were tested. Among these, ethanol has been found to be suitable one because the complex in micellar phase gets homogenized in less volume compared to acetonitrile and methanol. The ethanolassisted homogenized solution was diluted to $5 \mathrm{~mL}$, and its absorbance was measured at $690 \mathrm{~nm}$ against a reagent blank.

3.2. Efficiency of Clod Point Extraction. The efficiency of cloud point extraction mainly depends on the hydrophobic nature of the analyte, apparent equilibrium constants in the micellar medium, the kinetics of the complex formation, and the transference between the phases [17]. The arsenate along with molybdate forms arsenomolybdate in acidic condition which on reduction in presence of $\mathrm{Sb}$ (III) gives the arsenomolybdenum blue which is hydrophobic in nature. The high hydrophobicity of the complex in water is necessary for preconcentration by cloud point extraction. Under the optimal conditions, the highest extraction efficiency was obtained. The cloud point extraction efficiency increased with the hydrophobicity of the complexes and for the arsenomolybdenum blue complex it is nearly $100 \%$. The extraction efficiency of heteropoly acids like phosphomolybdenum blue and arsenomolybdenum blue (present method) has been found to be $100 \%$ because of their hydrophobic nature as well as complete partition due to the efficient binding of these
TABLE 1: Effect of foreign ions.

\begin{tabular}{lc}
\hline Interferent & Tolerance limit $(\mu \mathrm{g})$ \\
\hline $\mathrm{Ca}^{2+}, \mathrm{Cl}^{-}, \mathrm{Zn}^{2+}, \mathrm{Ni}^{2+}, \mathrm{Co}^{2+}, \mathrm{F}^{-}$ & $>2000$ \\
$\mathrm{Cd}^{2+}, \mathrm{SO}_{4}{ }^{2-}, \mathrm{I}^{-}, \mathrm{NO}_{3}{ }^{-}$ & $>1000$ \\
$\mathrm{Na}^{+}, \mathrm{K}^{+}, \mathrm{Mg}^{2+}, \mathrm{Fe}^{3+}, \mathrm{Fe}^{2+}$ & 800 \\
$\mathrm{~Pb}^{2+}, \mathrm{Ba}^{2+}, \mathrm{Cu}^{2+}, \mathrm{Al}^{3+}, \mathrm{Hg}^{2+}$ & 500 \\
\hline & $900^{\mathrm{a}}$ \\
$\mathrm{PO}_{4}{ }^{3-}$ & 10 \\
& $50^{\mathrm{b}}$ \\
$\mathrm{SiO}_{3}{ }^{2-}$ & 40 \\
\end{tabular}

${ }^{a}$ The white precipitate formed by the addition of the above metal ions was removed by centrifuging the solution, and then the reducing agent was added followed by the surfactant for preconcentrating the formed blue complex.

${ }^{b}$ The calcium nitrate was added before adding the molybdate so that phosphate does not form blue complex.

${ }^{\mathrm{c}}$ The tartaric acid was used to mask the silica interference, otherwise it forms silicomolybdenum blue and causes positive interference.

TABLE 2: Analytical merits of the proposed method.

Linear working range $\left(\mathrm{ng} \mathrm{mL} \mathrm{m}^{-1}\right)$

$10-200$

Limit of detection $\left(\mathrm{ng} \mathrm{mL} \mathrm{m}^{-1}\right)(3 \sigma, n=5)$

1.0

(Relative standard deviation \%) $(n=5)$

1.4

Maximum preconcentration factor

5

Improvement factor

24

complexes to the micellar phase. Thus, the enhancement factor which has been defined as the concentration ratio of the analyte in the final diluted surfactant rich phase is 24. This enhancement factor facilitates to bring the analyte concentration within the detectable range in the proposed method.

3.3. Interference Study. To check the suitability of the proposed method for application studies, the effect of common anions and cations was studied in the determination of arsenic. The anions like $\mathrm{Cl}^{-}, \mathrm{SO}_{4}{ }^{2-}, \mathrm{NO}_{3}{ }^{-}, \mathrm{CO}_{3}{ }^{2-}, \mathrm{F}^{-}$, and citrate did not interfere even at $1000 \mu \mathrm{g}$ level. However, $\mathrm{PO}_{4}{ }^{3-}$ and silica interfered positively as they also form heteropoly blue complexes. The phosphate and silicate interference was overcome by treating the sample solution with $1 \mathrm{~mL}$ each of $2 \%$ calcium nitrate and 3\% tartrate, respectively. The cationic species like $\mathrm{Ba}^{2+}, \mathrm{Pb}^{2+}, \mathrm{Hg}^{2+}, \mathrm{Al}^{3+}$, and $\mathrm{Cu}^{2+}$ form white precipitate which can be removed by centrifuging before adding surfactant. The other cations like $\mathrm{Fe}^{2+}, \mathrm{Ca}^{2+}$, $\mathrm{Mg}^{2+}, \mathrm{Cr}^{6+}, \mathrm{Zn}^{2+}$, and $\mathrm{Ni}^{2+}$ did not interfere even at $1000 \mu \mathrm{g}$. This method did not suffer any interference from glucose, citric acid, and amino acids like histidine, and so forth, which are commonly present in the urine samples (Table 1).

3.4. Analytical Merits. The analytical merits of the optimized method have been summarized in Table 2. The linear working range of the method has been found to be 10$200 \mathrm{ng} \mathrm{mL}^{-1}$. The limit of detection, relative standard deviation, preconcentration factor, and improvement factor of 
TABLE 3: Determination of arsenic from commercially procured chemicals.

\begin{tabular}{|c|c|c|c|}
\hline \multirow{2}{*}{ Sample } & \multirow{2}{*}{ Certified arsenic content (ng) } & \multicolumn{2}{|c|}{ Arsenic found (ng) } \\
\hline & & Proposed method & ICPAES method \\
\hline (1) Cupric sulphate ${ }^{a}$ (Analar grade) & 5000 & $4990 \pm 24$ & $4990 \pm 12$ \\
\hline (2) Cupric nitrate ${ }^{\mathrm{b}}$ (Analar grade) & 1000 & $990.0 \pm 9$ & $1140 \pm 18$ \\
\hline (3) Sodium hypophosphite Hydrated ${ }^{c}$ & 4000 & $4001 \pm 16$ & $3800 \pm 10$ \\
\hline (4) Amaranth dye & 3000 & $2900 \pm 12$ & $3000 \pm 15$ \\
\hline
\end{tabular}

$n=5$; the values given here are average of five measurements.

a Sample was procured from Glaxo Laboratories (India) Ltd., Mumbai with the following certified composition: Cl: 0.003\%; As: 0.0005\%; Fe: 0.005\%; Ni: $0.015 \%$.

${ }^{\mathrm{b}}$ Sample was procured from Glaxo Laboratories(India) Ltd., Mumbai with the following certified composition: Cl: 0.001\%; Sulphate: 0.0025\%; As: 0.0001\%; Fe: 0.005\%; Ni: 0.01\%; Ba: 0.005\%; Pd: 0.001\%, Bismuth: 0.001\%.

'Sample was procured from SD Fine Chem Ltd., Mumbai with the following certified composition. As: $0.0004 \%$; Pb: 0.001.

dSample was procured from SD Fine Chem Ltd., Mumbai with the following certified composition. As: 3 ppm; Pb: 10 ppm.

TABLE 4: Determination of arsenic in biological samples.

\begin{tabular}{|c|c|c|c|c|c|c|c|}
\hline \multirow{2}{*}{ Sample } & \multicolumn{2}{|c|}{ Total As (ng) } & \multirow[t]{2}{*}{$\mathrm{As}(\mathrm{V})$ added $(\mathrm{ng})$} & \multicolumn{2}{|c|}{ Total As(V) found (ng) } & \multicolumn{2}{|c|}{ Recovery (\%) } \\
\hline & Proposed method & ICPAES method & & $\begin{array}{c}\text { Proposed } \\
\text { method }\end{array}$ & ICPAES method & Proposed method & $\begin{array}{l}\text { ICPAES } \\
\text { method }\end{array}$ \\
\hline Hair* & ND & ND & 20 & $19.9 \pm 1.2$ & $20.0 \pm 1.6$ & 99.5 & 100 \\
\hline Nail $^{*}$ & ND & ND & 10 & $9.2 \pm 1.9$ & $9.8 \pm 1.1$ & 96.2 & 98.0 \\
\hline Urine $^{\dagger}$ & $\mathrm{ND}$ & $\mathrm{ND}$ & 20 & $19.6 \pm 1.2$ & $20.3 \pm 1.2$ & 98.0 & 101.5 \\
\hline
\end{tabular}

$n=5$; the values given here are average of five measurements.

ND: Not detected.

* Concentration in $\mathrm{ng} \mathrm{g}^{-1}$.

${ }^{\dagger}$ Concentration in $\mathrm{ng} \mathrm{mL}^{-1}$.

TABLE 5: Determination of arsenic in different environmental samples.

\begin{tabular}{|c|c|c|c|c|c|c|c|c|}
\hline \multirow[t]{2}{*}{ Sample } & \multirow{2}{*}{$\begin{array}{l}\text { As }(\mathrm{V}) \text { found } \\
\text { in samples } \\
\text { Proposed } \\
\text { method } \\
\end{array}$} & \multicolumn{2}{|c|}{$\begin{array}{l}\text { As }(\mathrm{III})+\operatorname{As}(\mathrm{V}) \text { found } \\
\quad \text { in samples }\end{array}$} & \multirow[t]{2}{*}{$\begin{array}{c}\text { As }(\mathrm{V}) \\
\text { added (ng) }\end{array}$} & \multicolumn{2}{|c|}{ Total arsenic } & \multicolumn{2}{|c|}{ Recovery (\%) } \\
\hline & & $\begin{array}{l}\text { Proposed } \\
\text { method }\end{array}$ & $\begin{array}{l}\text { ICPAES } \\
\text { method }\end{array}$ & & $\begin{array}{c}\text { Proposed } \\
\text { method }\end{array}$ & $\begin{array}{l}\text { ICPAES } \\
\text { method }\end{array}$ & $\begin{array}{l}\text { Proposed } \\
\text { method }\end{array}$ & $\begin{array}{l}\text { ICPAES } \\
\text { method }\end{array}$ \\
\hline Polluted water* & ND & $500 \pm 12$ & $499 \pm 13$ & - & - & - & - & - \\
\hline Bore well water* & ND & $200 \pm 13$ & $200 \pm 11$ & 20 & $220 \pm 12$ & $220 \pm 12$ & 100 & 100 \\
\hline Polluted soil ${ }^{\dagger}$ & $32 \pm 2.0$ & $99.0 \pm 9.1$ & $98.0 \pm 8.3$ & - & - & - & - & - \\
\hline $\begin{array}{l}\text { Spinach leaves }{ }^{\dagger} \\
\text { (Spinacia oleracea) }\end{array}$ & ND & $210 \pm 12$ & $209 \pm 12$ & 20 & $230 \pm 10$ & $229 \pm 12$ & 100 & 99.5 \\
\hline $\begin{array}{l}\text { Tomato leaves }{ }^{\dagger} \\
\text { (Lycopersicon } \\
\text { esculentum) }\end{array}$ & ND & $500 \pm 15$ & $449 \pm 11$ & 10 & $590 \pm 12$ & $600 \pm 15$ & 98.3 & 100 \\
\hline
\end{tabular}

$n=5$; the values given here are average of five measurements.

ND: Not detected.

*Concentration in $\mathrm{ng} \mathrm{mL}^{-1}$.

${ }^{\dagger}$ Concentration in $\mathrm{ng} \mathrm{g}^{-1}$.

the method were found to be $1.0 \mathrm{ng} \mathrm{mL}^{-1}, 1.4$ for $25 \mathrm{ng}$ arsenic, 5 and 24, respectively.

3.5. Application Study. In order to check the reliability of the proposed method, it was applied to determine arsenic content in the commercial chemicals where arsenic quantity is certified. The recovery studies were carried out by spiking the biological samples like human urine, human nail, and human hair samples with known quantities of arsenic. These results were found to be compared with the results of ICPAES method which are in good agreement. The arsenic content in surface water, ground water, soil, and vegetable samples were also determined (Tables 3, 4, and 5).

3.5.1. Water Samples. The ground water contamination with arsenic mainly depends on the nature of soil as well as the human activity nearby the region. Arsenic-based paints have been extensively used in painting clay idols throughout the world. These idols were submerged in the lake water or ponds after their procession during the selective festival season in 
TABLE 6: Comparison of the proposed method with other methods.

\begin{tabular}{lcccc}
\hline Method & Linear range $\left(\mathrm{ng} \mathrm{mL}^{-1}\right)$ & $\begin{array}{c}\text { Detection limit } \\
\left(\mathrm{ng} \mathrm{m}^{-1}\right)\end{array}$ & $\begin{array}{c}\text { Preconcentration } \\
\text { factor }\end{array}$ & References \\
\hline (1) Ion-Pair extraction/spectrophotometry & $50-800$ & - & 5.0 & {$[10]$} \\
(2) Chemiluminescent method & $0-100$ & 0.4 & 12.5 & {$[11]$} \\
(3) Spectrophotometry & $0-300$ & 4.0 & - & {$[12]$} \\
(4) Cloud point extraction/spectrophotometry & $10-200$ & 1.0 & 5.0 & $\begin{array}{c}\text { Proposed } \\
\text { method }\end{array}$ \\
\hline
\end{tabular}

India and some other parts of world. When these clay idols were submerged, the water bodies as well as the soil sledges get contaminated with the arsenic.

3.5.2. Soil Samples. The soil can get contaminated with arsenic by various means. The agricultural soil gets contamination with arsenic by means of manures and agricultural sprays. The soil sludge in our study was collected from the pond beds where painted clays idols were dumped after festivals. These idols slowly dissolve, and pond bed collects clay material containing arsenic.

3.5.3. Vegetable Samples. The plant uptake capacity for arsenic depends mainly on the level of arsenic present in the soil as well as the use of arsenic contaminated water. The arsenic content in spinach leaves and tomato leaves was determined by following the procedure discussed above.

3.5.4. Biological Samples. Arsenic can be measured in human urine, hair, and nail samples to monitor excessive environmental or occupational exposure, to confirm a diagnosis of poisoning in hospitalized victims or to assist in the forensic investigation in case of fatal overdosage. Organic arsenic compounds tend to be eliminated in the urine in unchanged form, while inorganic forms are largely converted to organic arsenic compounds in the body prior to urinary excretion.

\section{Conclusions}

A simple, highly sensitive cloud point extractive spectrophotometric procedure for trace level arsenic quantification in different matrices has been reported. The method is based on the cloud-point-mediated preconcentration of the arsenomolybdenum blue complex and measuring its absorbance. The method can be employed to detect the inorganic arsenic species in various environmental matrices at nanogram levels. This method is much more sensitive than any other spectrophotometric method reported till now including arsenomolybdenum blue method. The use of surfactant in the proposed method is ecofriendly and nontoxic when compared to the conventionally used organic solvents for extraction of the analyte. It provides wide linear range in comparison with some of the reported methods (Table 6). The results obtained by the proposed method have been compared with the ICPAES method, and the measured arsenic levels from different natural samples were found to be in good agreement.

\section{Acknowledgments}

The authors acknowledge the financial support and award of the fellowship to K. S. Kumar by the University Grants Commission (UGC), New Delhi, India. The authors thank Mr. Vijayarajulu, Geological Survey of India, Government of India, Bangalore, India for carrying out ICPAES analysis.

\section{References}

[1] K. C. Makris, P. Punamiya, D. Sarkar, and R. Datta, "Novel colorimetric method overcoming phosphorus interference during trace arsenic analysis in soil solution," Analyst, vol. 133, no. 2, pp. 191-196, 2008.

[2] H. V. Aposhian, R. A. Zakharyan, M. D. Avram, M. J. Kopplin, and M. L. Wollenberg, "Oxidation and detoxification of trivalent arsenic species," Toxicology and Applied Pharmacology, vol. 193, no. 1, pp. 1-8, 2003.

[3] B. K. Mandal and K. T. Suzuki, "Arsenic round the world: a review," Talanta, vol. 58, no. 1, pp. 201-235, 2002.

[4] F. Shemirani, M. Baghdadi, and M. Ramezani, "Preconcentration and determination of ultra trace amounts of arsenic(III) and $\operatorname{arsenic}(\mathrm{V})$ in tap water and total arsenic in biological samples by cloud point extraction and electrothermal atomic absorption spectrometry," Talanta, vol. 65, no. 4, pp. 882-887, 2005.

[5] J. A. Baig, T. G. Kazi, M. B. Arain et al., "Inorganic arsenic speciation in groundwater samples using electrothermal atomic spectrometry following selective separation and cloud point extraction," Analytical Sciences, vol. 27, no. 4, pp. 439-445, 2011.

[6] A. Fisher, P. S. Goodall, M. W. Hinds, S. M. Nelms, and D. M. Penny, "Atomic spectrometry update. Industrial analysis: metals, chemicals and advanced materials," Journal of Analytical Atomic Spectrometry, vol. 18, no. 12, pp. 1497-1528, 2003.

[7] J. M. Costa-Fernández, N. H. Bings, A. M. Leach, and G. M. Hieftje, "Rapid simultaneous multielemental speciation by capillary electrophoresis coupled to inductively coupled plasma time-of-flight mass spectrometry," Journal of Analytical Atomic Spectrometry, vol. 15, no. 9, pp. 1063-1068, 2000.

[8] M. de Almeida Bezerra, M. A. Zezzi Arruda, and S. L. Costa Ferreira, "Cloud point extraction as a procedure of separation and pre-concentration for metal determination using spectroanalytical techniques: a review," Applied Spectroscopy Reviews, vol. 40, no. 4, pp. 269-299, 2005.

[9] Suhendrayatna, A. Ohki, T. Nakajima, and S. Maeda, "Studies on the accumulation and transformation of arsenic in freshwater organisms II. Accumulation and transformation of arsenic compounds by Tilapia mossambica," Chemosphere, vol. 46, no. 2, pp. 325-331, 2002. 
[10] T. Pal, N. R. Jana, and T. Sau, "Determination of arsenic in aqueous samples with solvent extraction of ion associates," Analytical Proceedings including Analytical Communications, vol. 32, no. 9, pp. 369-370, 1995.

[11] A. Hashem, T. Jodai, S.-I. Ohira, K. Wakuda, and K. Toda, "High sensitivity arsenic analyzer based on liquid-reagent-free hydride generation and chemiluminescence detection for onsite water analysis," Analytical Sciences, vol. 27, no. 7, pp. 733738, 2011.

[12] K. Morita and E. Kaneko, "Spectrophotometric determination of arsenic in water samples based on micro particle formation of ethyl violet-molybdoarsenate," Analytical Sciences, vol. 22, no. 8, pp. 1085-1089, 2006.

[13] M. Pandurangappa and K. Suresh Kumar, "Micellar mediated trace level mercury quantification through the rhodamine B hydrazide spirolactam ring opening process," Analytical Methods, vol. 3, no. 3, pp. 715-723, 2011.

[14] R. A. Meyers, Encyclopedia of Analytical Chemistry, vol. 12, John-Wiley, New York, NY, USA, 2000.

[15] A. Afkhami and R. Norooz-Asl, "Cloud point extraction for the spectrophotometric determination of phosphorus(V) in water samples," Journal of Hazardous Materials, vol. 167, no. 1-3, pp. 752-755, 2009.

[16] E. K. Paleologos, D. L. Giokas, S. M. Tzouwara-Karayanni, and M. I. Karayannis, "Micelle mediated methodology for the determination of free and bound iron in wines by flame atomic absorption spectrometry," Analytica Chimica Acta, vol. 458, no. 1, pp. 241-248, 2002.

[17] R. Carabias-Martinez, E. Rodriguez-Gonzalo, J. DominguezAlvarez, and J. Hernández-Méndez, "Cloud point extraction as a preconcentration step prior to capillary electrophoresis," Analytical Chemistry, vol. 71, no. 13, pp. 2468-2474, 1999. 


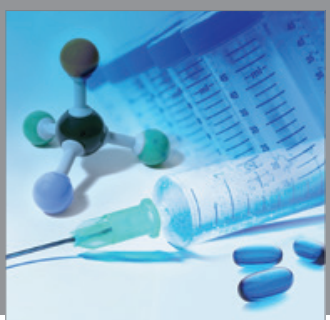

International Journal of

Medicinal Chemistry

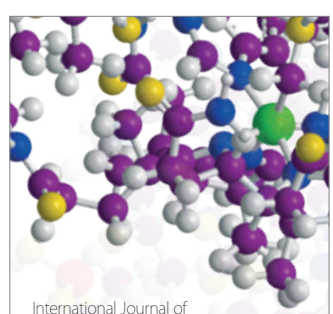

Carbohydrate Chemistry

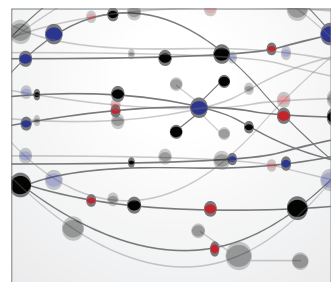

The Scientific World Journal
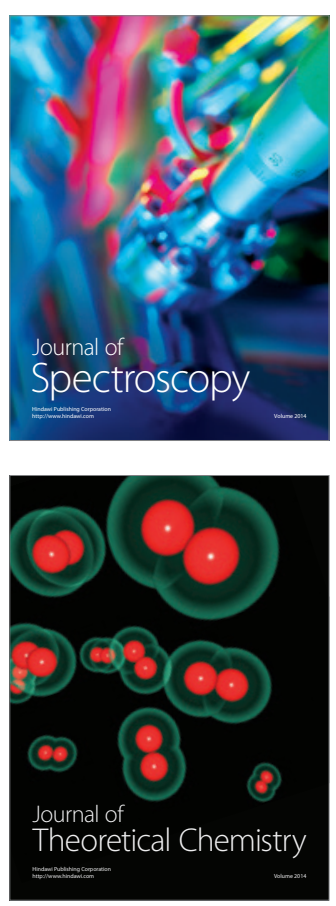
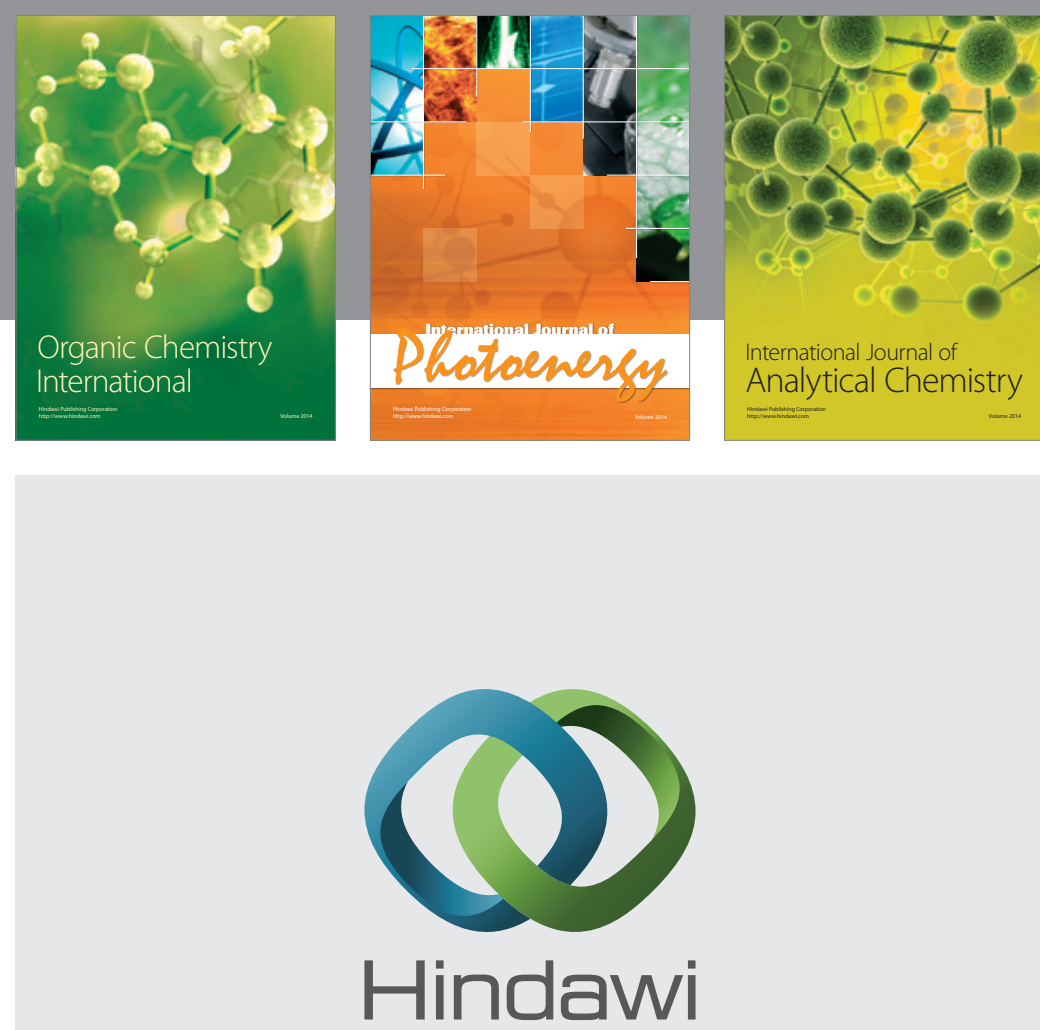

Submit your manuscripts at

http://www.hindawi.com
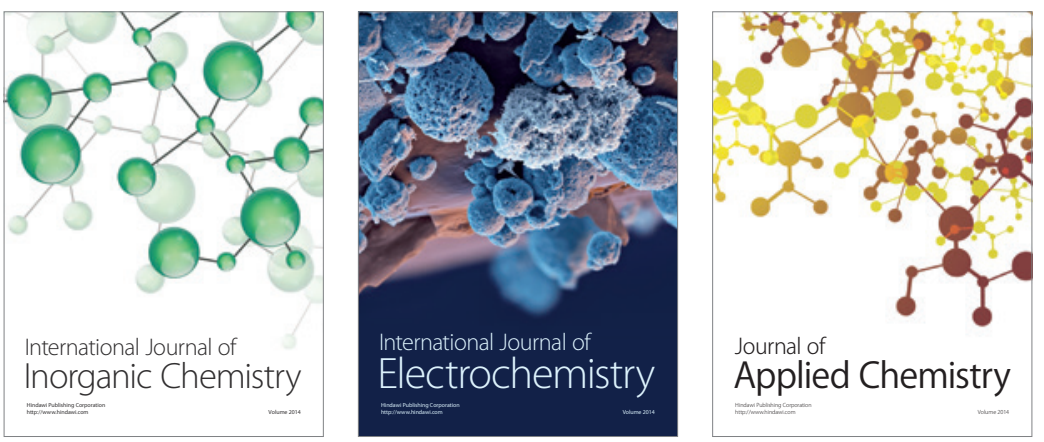

Journal of

Applied Chemistry
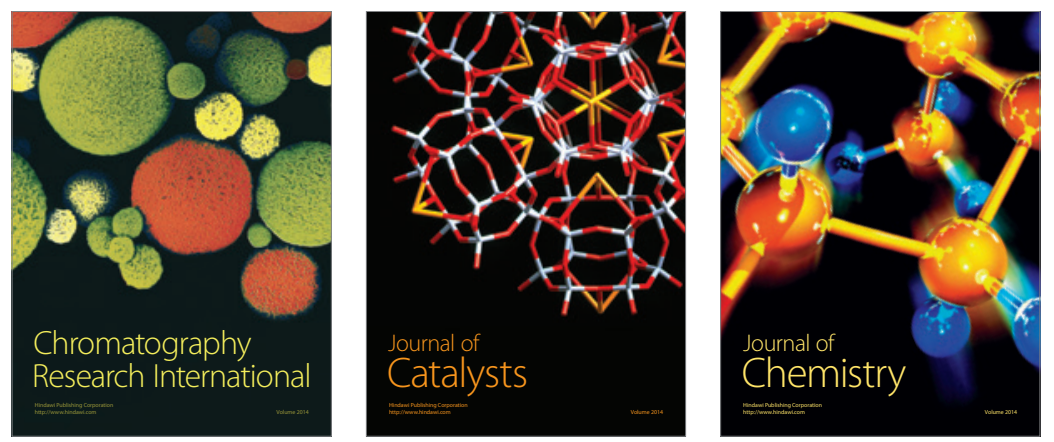
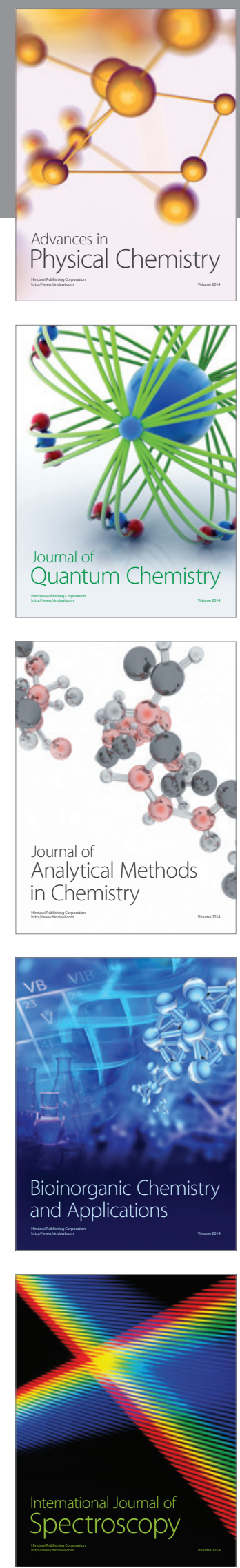